\title{
PHẪU THUẬT NộI SOI LỒNG NGỰC ROBOT DÙNG ĐƯờNG VÀO NộI SOI THÔNG THƯờnG
}

Vũ Hũu Vĩnh*, Đặng Đình Minh Thanh*, Nguyễn Viết Đăng Quang*, Truoong Cao Nguyê* *

\section{TÓM TÁ́T}

Phẫu thuật nội soi lồng ngực (Video asisted thoracic surgery $=$ VATS) đã được sử dụng rộng rãi và khẳng định được hiệu quả so với mổ mở truyền thống. Phẫu thuật nội soi lồng ngực robot (robotic VATS = r-VATS) là phẫu thuật nội soi sử dụng robot được con người điều khiển. R-VATSđã được áp dụng ở nhiều nơi trên thế giới nhưng ở Việt nam còn chưa được áp dụng rộng rãi. Chúng tôi bắt đầu áp dụng $\mathrm{r}$-VATS từ được từ tháng 7 năm 2018, dùng đường vào của nội soi thông thường và báo cáo kết quả bước đầusau 18 tháng với 116 trường hợp được phẫu thuật. Cắt thuỳ phổi $57 \mathrm{ca}$, cắt phổi hình chêm $9 \mathrm{ca}$; cắt tuyến ức $19 \mathrm{ca}$, cắt $\mathrm{u}$ trung thất $28 \mathrm{ca}$, cắt thực quản là $1 \mathrm{ca}$, cắt $\mathrm{u}$ cơ trơn thực quản $1 \mathrm{ca}$, và khâu gấp nếp cơ hoành 1 ca. 110 trường hợp có kết quả tốt, không có biến chứng, 5 ca có tràn khí kéo dài trên 5 ngày. Tử vong 1 trường hợp sau mổ 35 ngày do viêm phổi. Thời gian mổ tương đương phẫu thuật nội soi thông thường. Thời gian rút ống dẫn lưu trung bình là 2 ngày.Thời gian xuất viện tương đương với phẫu thuật nội soi thông thường.

\section{SUMMARY}

Video asisted thoracic surgery (VATS) has been widely used and confirmed to be effective and less invasive compared to traditional open surgery. Robotic thora surgery (robotic VATS $=$ r-VATS) is actually a VATSusing a robotthat is controlled by human surgeon. R-VATS has been applied widely worldwide but still lessin Vietnam. Wehave started r-VATS since July 2018, using conventionalthoracoscopicaccesses (trocars) and reported our initial results after 18 months with 116 cases. Lobectomy 57 cases, wedge resection 9 cases; thymectomy 19 cases,mediastinal tumor resection 28 cases, esophagectomy 1 case, esophageal leiomyoma resection 1 case, and diaphragm plication 1 case. 110 cases with good results, no complications, 5 cases with prolong airleak requiring chest tube for over 5 days. One died after 35 days due to pneumonia. The surgery time is equivalent to cVATS. Average chest tube removalwas 2 days. Post-op hospital staywas equivalent to c-VATS.

\section{I. ĐẶT VẤN ĐỂ}

Phẫu thuật nội soi lồng ngực đã chứng minh hiệu quả và tính chất ít xâm lấn hơn hẳn so với mổ mở (mở ngực hoặc chẻ xương ức). Về hiệu quả nó hoàn toàn tương đương mổ mở trong khi về phương diện xâm lấn của phẫu thuật, nó ưu việt hơn. Do ít xâm lấn, nó làm giảm nguy cơ tai biến ở những trường hợp có nguy cơ cao như người già, có bệnh lý phối hợp. Đặc biệt tính giảm đauvà thẩm mỹ sau mổ, sự phục hồi sau mổ thì phẫu thuật nội soi lồng ngực đã chứng minh sự hơn hẳn so với mổ mở kinh điển.

Phẫu thuật robot nội soi lồng ngực, thực chất là phẫu thuật nội soi lồng ngực có sử dụng robot hỗ trợ cho phẫu thuật viên.

Về mặt ngôn từ phẫu thuật nội soi lồng ngực là Video - assisted thoracoscopic surgery (VATS), phẫu thuật ít xâm lấn là Minimally invasive thoracic surgery (MITS) hoặc Minimally invasive

\footnotetext{
* Khoa ngoại Lồng ngực, Bệnh viện Chơ rẫy Ngườ chịu trách nhiệm khoa học: PGS.TS Vũ Hũu Vĩnh Ngày nhận bài: 01/02/2019 - Ngày Cho Phép Đăng: 23/03/2020 Phản Biện Khoa học: PGS.TS. Đặng Ngoc Hùng GS.TS. Lê Ngọc Thành
} 
surgery (MIS) còn với robot, trong y văn thường đề cập làrobotic - assisted thoracic surgery (RATS). Ở bài này, chúng tôi gọi phẫu thuật nội soi lồng ngực robot là r-VATS (robotic Video-assisted thoracoscopic surgery) và khi đề cập đến r-VATS thì VATS trở thành c- VATS (conventional Videoassisted thoracoscopic surgery).

\section{PHƯƠNG PHÁP}

Robot được chúng tôi sử dụng là hệ thống Si của hãng Da Vinci, Mỹ, với 4 cánh tay. Với việc dùng 4 cánh tay, sẽ có 5 trocar ( 5 ports) được sử dụng để đưa 3 dụng cụ phẫu thuật (cánh tay $1,2$ và 3$)$, một trocar (12 mm ở hệ thống $\mathrm{Si}$ ) cho camera và một trocar cho hỗ trợ từ con người (assistant). Lồ hỗ trợ thường là trocar $12 \mathrm{~mm}$, qua đó phẫu thuật viên phụ mổ có thể hút, vén hỗ trợ cho phẫu thuật viên chính ngồi ở bàn điều khiển hoặc đưa stapler vào. Theo khuyến cáo của hãng và nhiều phẫu thuật viên trên thế giới, các trocar được đặt thẳng hàng ở khoang liên sườn 8 cho cả bên trái lẫn bên phải. Trocar hỗ trợ thường được đặt ở khoang liên sườn 9 hoặc dưới mạng sườn (dưới xương sườn 10). Các trocar được bịt kín để có thể bơm $\mathrm{CO} 2$ từ $8-10 \mathrm{mmHg}$ vào khoang lồng ngực làm xẹp phổi. Cuối cuộc mổ, một trong các 1ố trocar được rạch rộng thêm để lấy bệnh phẩm ra. (H. $1 \mathrm{~A}$ và $\mathrm{B})$.

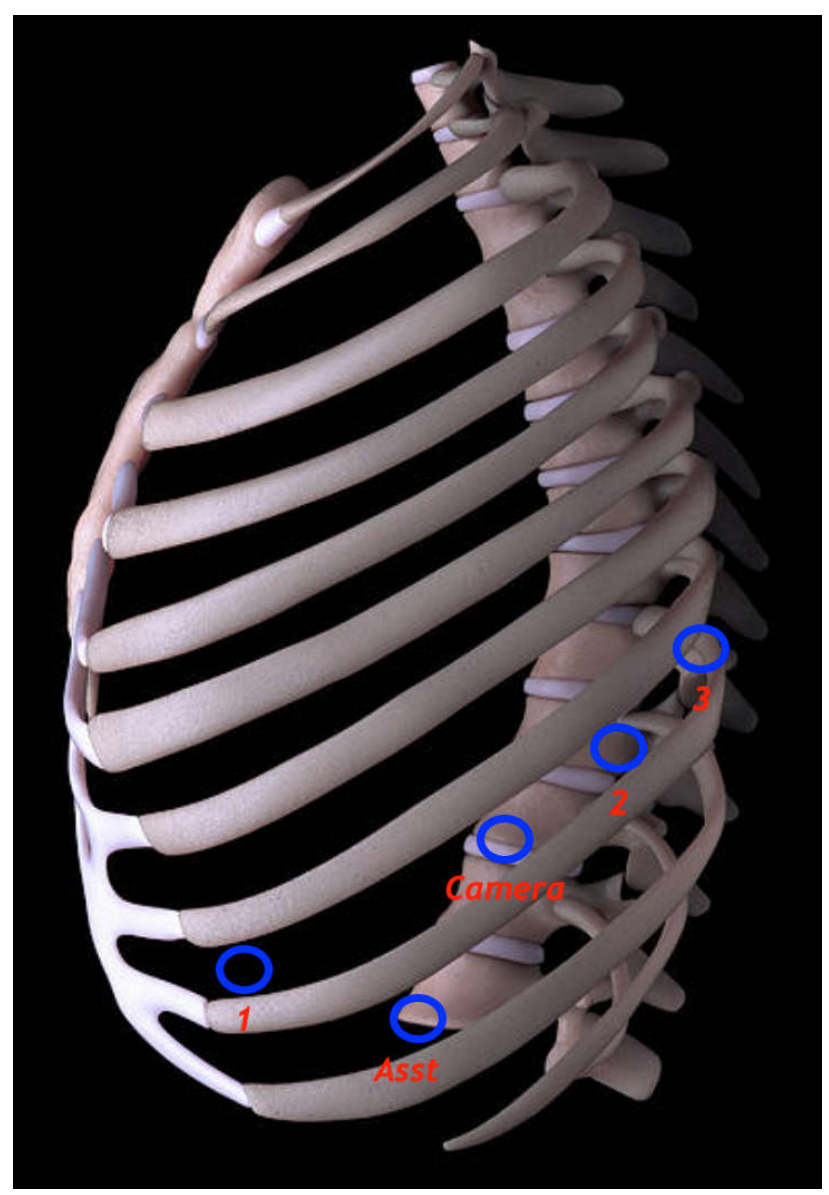

H.1 A các vị trí đặt trocar cho ngực trái kiểu thẳng hàng. 1,2,3: Cánh tay robot 1,2 và 3 với các dụng cụ đi kèm. Assit: cổng hỗ trợ, trocar kín $12 \mathrm{~mm}$, phẫu thuật viên phụ dùng cổng này để hỗ trợ phẫu thuật như đưa dụng cụ kim, chỉ, gạc, hút, kéo vén khi cần thiết và cũng là cổng để dùngstapler cắt mạch máu và nhu mô, khí phế quản 


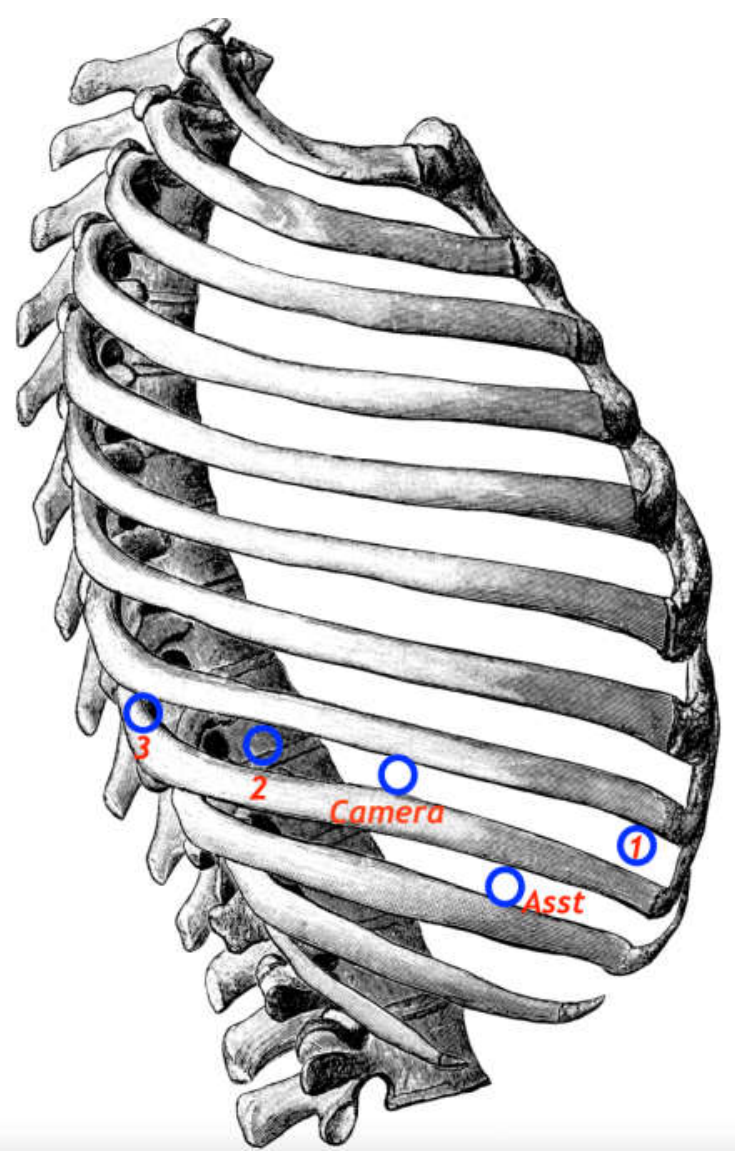

H. $1 \mathrm{~B}$ các vị trí trocar cho ngực phải kiểu thẳng hàng

Cũng có những những tác giả đặt cao hơn một liên sườn (khoang liên sườn 7) nhưng cũng là kiểu thẳng hàng $(\mathrm{H} .1 \mathrm{C})$

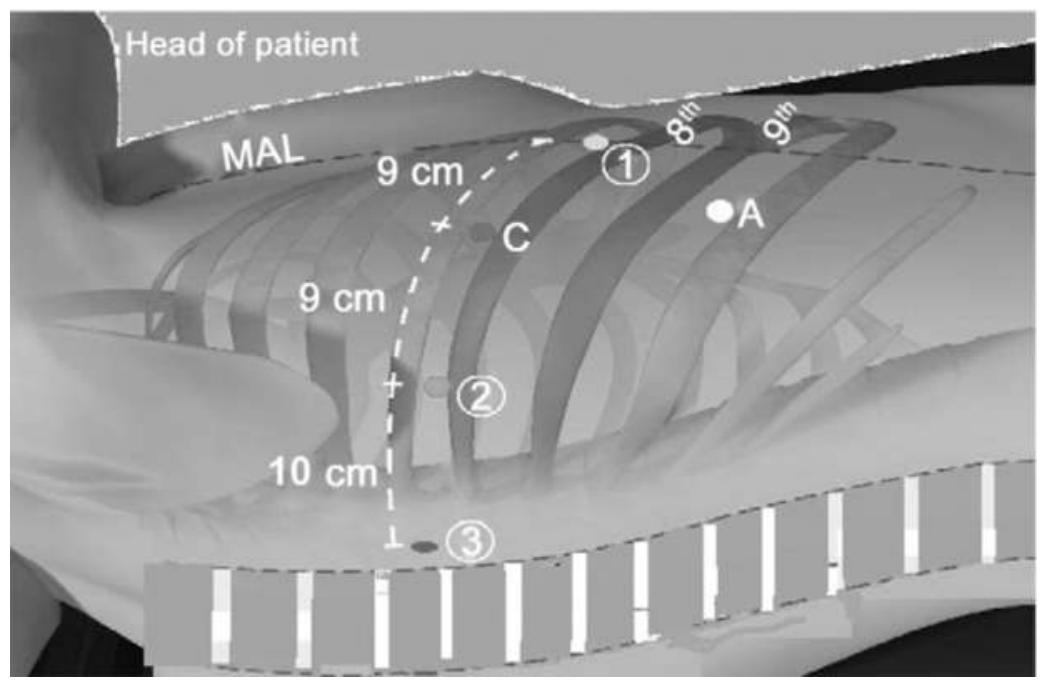

H. 1 C: cách đặt trocar ở liên sườn 7 theo tác giả Cerfolio (Robert J. Cerfolio, MD, Ayesha S. Bryant, MD, and Douglas J. Minnich, MD. Starting a Robotic Program in General Thoracic Surgery: Why, How, and Lessons Learned. Ann Thorac Surg 2011;91:1729-37) 
Chúng tôi chỉ dùng 4 lỗ trong phẫu thuật nội soi robot lồng ngực. Đối với phẫu thuật các bệnh lý ở khoang lồng ngực như cắt thuỳ phổi, cắt thực quản, cắt $\mathrm{u}$ cơ trơn thực quản, cắt $\mathrm{u}$ trung thất sau hoặc u trung thất lệch một bên trong lồng ngưc, chúng tôi để bệnh nhân nằm nghiêng. Đặt các trocar theo vị trí nội soi kinh điển thông thường hình tam giác. Bao gồm 2 trocar cho 2 dụng cụ (cánh tay 1 và 2), một trocar cho camera và một được mở rộng $1,5 \mathrm{~cm}$ ngay từ đầu cuộc mổ với dụng cụ vén vết mổ (wound retractor) dùng làm cổng hỗ trợ để phẫu thuật viên phụ xử dụng để hút hoặc đưa dụng cụ kéo, vén vào trợ giúp phẫu thuật viên chính trong phẫu thuật . Cuối cuộc mổ, lỗ $1,5 \mathrm{~cm}$ này đủ để lấy bệnh phẩm ra mà không cần phải rạch thêm $(\mathrm{H} .2 \mathrm{~A}$ và $\mathrm{B})$. Do có dùng dụng cụ vén vết mổ nên khoang ngực luôn thông với khí trời, không dùng bơm khí $\mathrm{CO} 2$ được, phổi bên mổ xẹp được nhờthông khí 1 bên phổi (bên đối diện) với ống nội phế quản 2 nòng, có cuff hỗ trợ (cuff thứ 3 ) để định vị ống vào chính xác phế quản gốc bên cần đặt. ( $\mathrm{H}$. 3). Ống nội phế quản 2 nòng này giúp phổi xẹp tốt, việc đặt ống đơn giản, hiệu quả và chính xác.

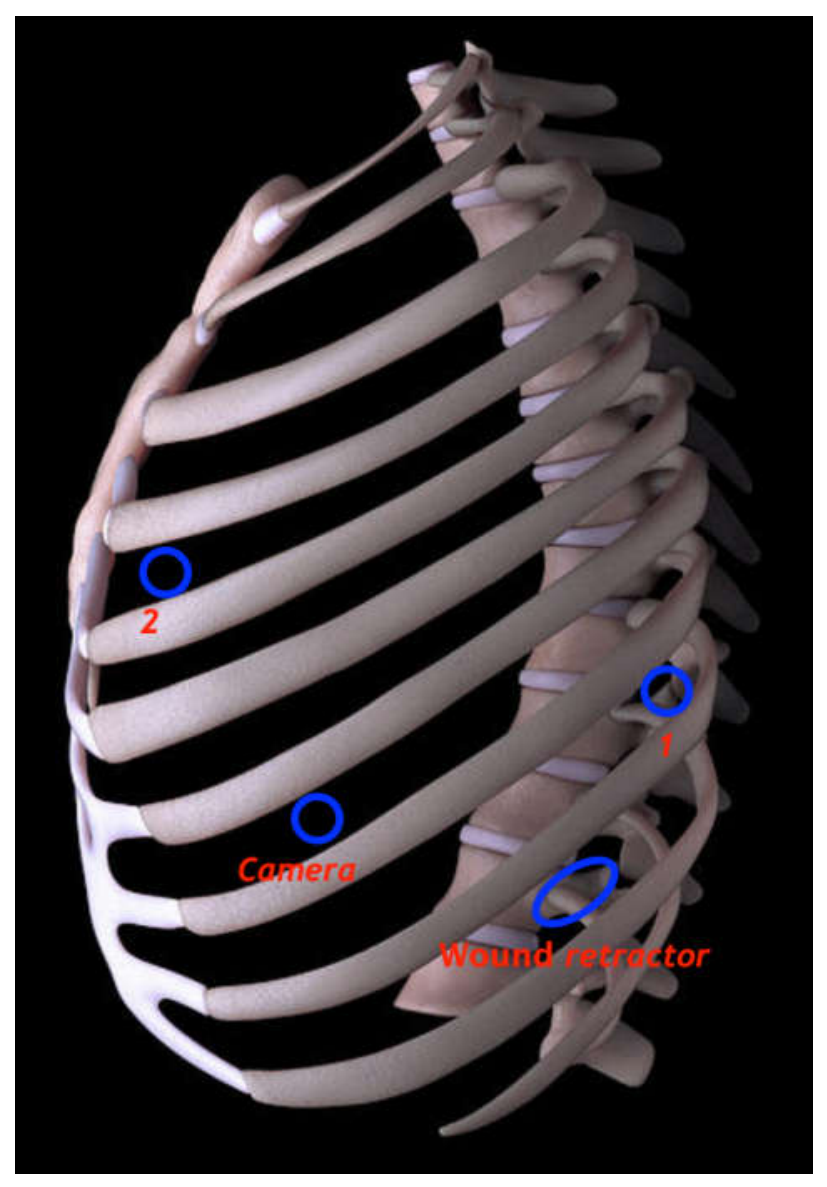

H. 2 A. Các vị trí đặt trocar hình tam giác theo kiểu phẫu thuật nội soi thông thường cho bên ngực trái. 1,2: các cánh tay robot 1 và 2 (chỉ dùng 2 cánh tay). Wound retractor: lỗ $1,5 \mathrm{~cm}$ với dụng cụ vén vết mổ, qua đó phẫu thuật viên phụ có thể dùng để kéo vén phụ khi cần, hút, đưa dụng cụ hỗ trợ như gạc, kim chỉ... vào, và cũng là cổng để sử dụng stapler cho mạch máu, nhu mô và khí phế quản. 


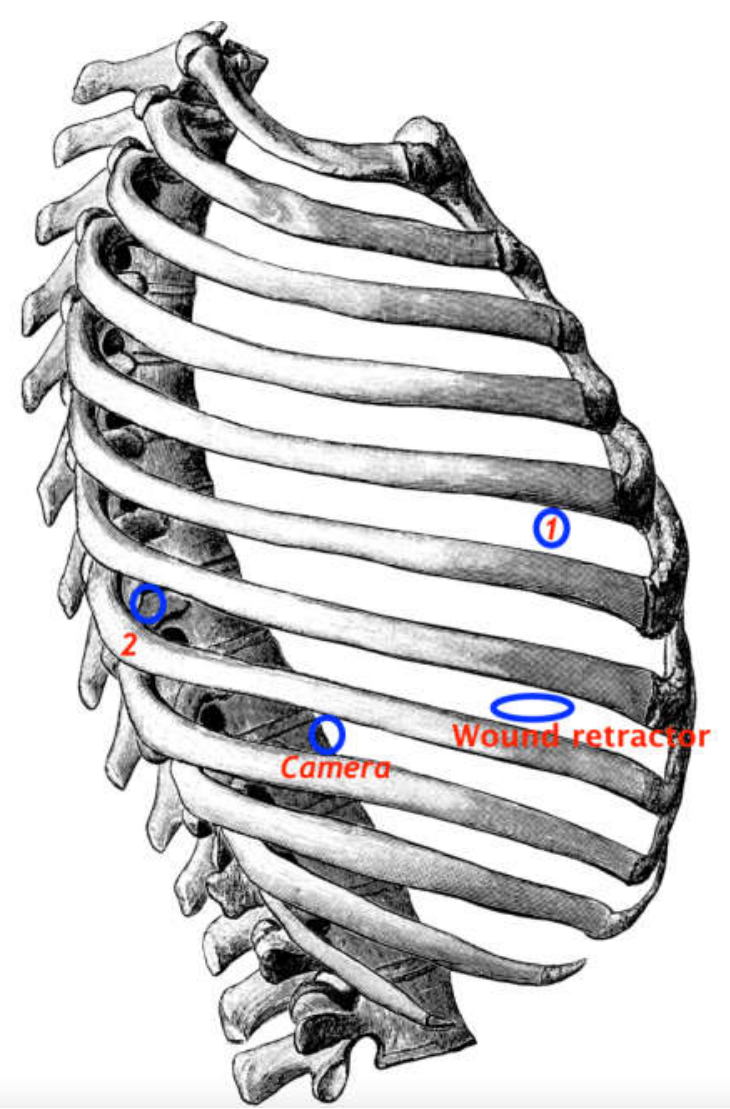

H.2 B. Các vị trí đặt trocar hình tam giác theo kiểu nội soi thông thường cho bên ngực phải

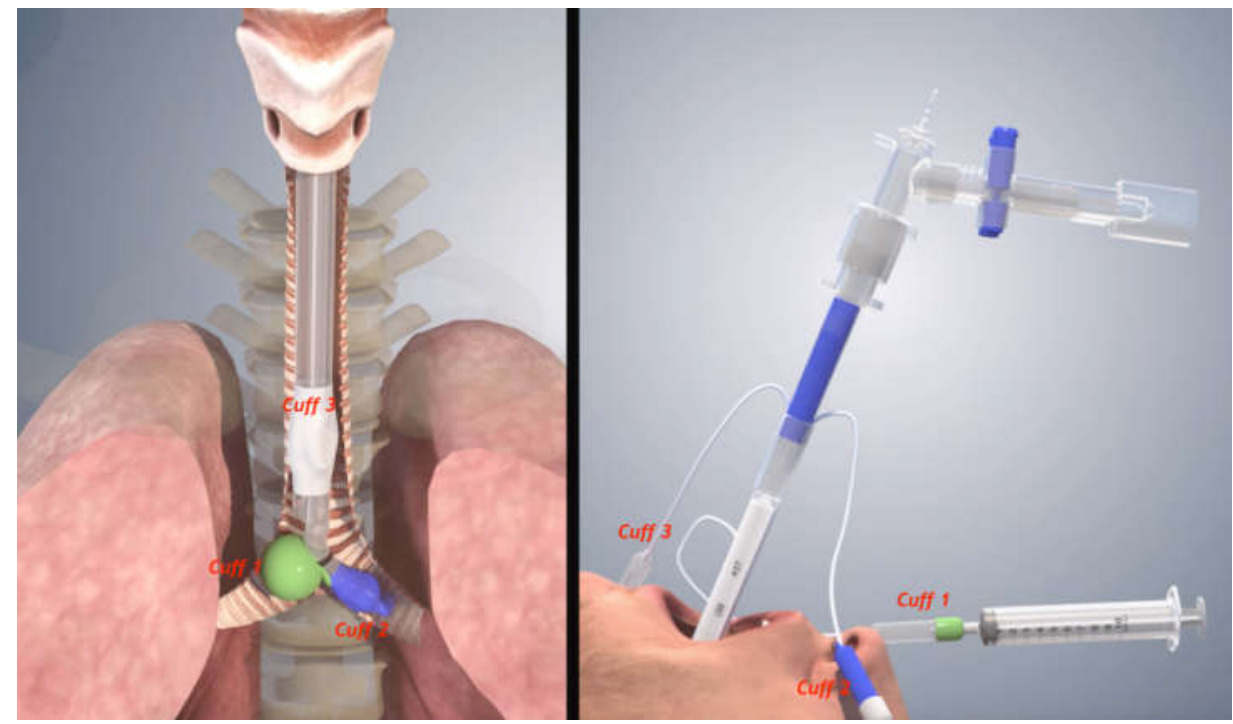

H. 3 Ống nội phế quản 2 nòng với 3 cuff giúp định vị chính xác vị trí ống trong 1 bên phế quản gốc giúp xẹp phổi 1 bên hiệu quả và dễ dàng 
Đối với việc phẫu thuật ở vùng trung thất trước, như cắt u trung thất trước, cắt tuyến ức điều trị bệnh nhược cơ ( kể cả có $u$ và không có u tuyến ức kèm theo), chúng tôi để bệnh nhân nằm ngửa, thông khí phổi 2 bên trong lúc mổ nhưng vẫn được đặt ống nội phế quản 2 nòng để thông khí 1 bên khi cần thiết. Trocar camera được đặt dưới mũi ức, 2 cánh tay 1 và 2 để 2 bên ngực, trocar hỗ trợ $12 \mathrm{~mm}$ kín đặt hoặc bên phải hoặc bên trái. Hệ thống kín để có thể bơm khí $\mathrm{CO} 2$ làm rộng và rõ trường mổ ở trung thất trước mà không cần phải làm xẹp một bên phổi nào đó. (H. 4).

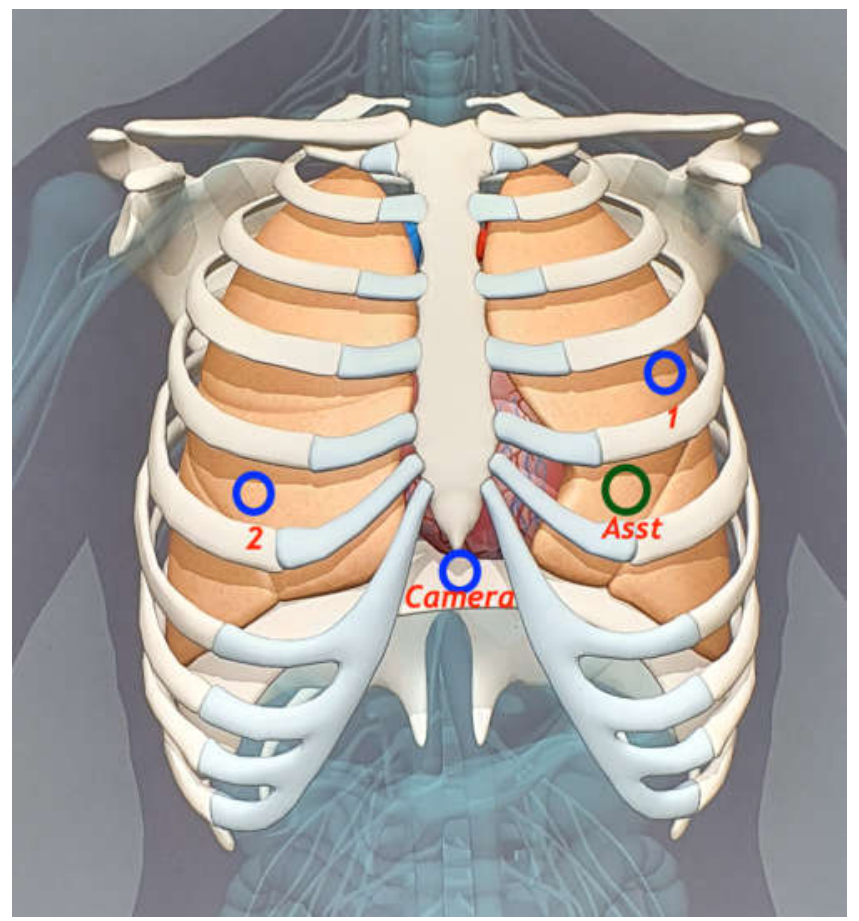

H. 4 Các vị trí đặt trocar trong phẫu thuật vùng trung thất trước kiểu dưới mũi ức với bơm khí trong khoang lồng ngực và thông khí cả 2 phổi trong phẫu thuật. 1,2: các cánh tay robot 1 và 2;Asst: cổng hỗ trợ, trocar kín $12 \mathrm{~mm}$, phẫu thuật viên phụ dùng cổng này để hỗ trợ phẫu thuật như đưa dụng cụ kim, chỉ, gạc, hút, kéo vén và cũng là cổng để dùng stapler khi cần thiết.

\section{KẾT QUẢ}

Từ tháng 7/2018 đến 1/2020, có 116 bệnh nhân được phẫu thuật, 66 nam và 50 nữ. Trong đó cắt thuỳ phổi là $57 \mathrm{ca}$, cắt phổi hình chêm là $9 \mathrm{ca}$, cắt tuyến ức (có và không có $\mathrm{u}$ ) là $19 \mathrm{ca}$, cắt $\mathrm{u}$ trung thất là $28 \mathrm{ca}$, cắt thực quản tạo hình bằng dạ dày là $1 \mathrm{ca}$, cắt $\mathrm{u}$ cơ trơn thực quản là $1 \mathrm{ca}$, gấp nếp cơ hoành là 1 ca. (table 1)

\section{Bảng 1. Số lượng các ca mổ loại phẫu thuật.}

\begin{tabular}{|c|c|c|c|c|c|c|c|}
\hline $\begin{array}{c}\text { Cắt thực } \\
\text { quản }\end{array}$ & $\begin{array}{c}\text { Cắt u cơ } \\
\text { trơn thực } \\
\text { quản }\end{array}$ & $\begin{array}{c}\text { Cắt thuỳ } \\
\text { phồi }\end{array}$ & $\begin{array}{c}\text { Cắt phổi } \\
\text { hình chêm }\end{array}$ & $\begin{array}{c}\text { Cắt tuyến ức } \\
\text { (có và không } \\
\text { u kèm theo) }\end{array}$ & $\begin{array}{c}\text { Cắt u } \\
\text { trung } \\
\text { thất }\end{array}$ & $\begin{array}{c}\text { Gấp nếp } \\
\text { cơ hoành }\end{array}$ & Tổng \\
\hline 1 & 1 & 57 & 9 & 19 & 28 & 1 & 116 \\
\hline
\end{tabular}


Kết quả mổ tốt ở 110 trường hợp, đạt mục đích phẫu thuật nội soi hoàn toàn, không biến chứng, thời gian rút ống dẫn lưu trung bình là 2 ngày. Có 5 ca cần để ống kéo dài trên 5 ngày, được coi như tràn khí kéo dài sau mổ. Những ca này có thời gian trung bình rút ống là 6 ngày. Sau rút ổn định, xuất viện. Có 1 ca tử vong do u phổi xâm lấn phế quản gốc phải, sau mổ bệnh nhân được rút ống, chuẩn bị cho xuất viện thì mắc viêm phổi bệnh viện. Bệnh nhân được điều trị viêm phổi nặng, kéo dài và tử vong sau 1 tháng.

Tuy không có thang đánh giá nhưng các bệnh nhân đều ghi nhận rất ít đau sau mổ, phục hồi nhanh và hài lòng với việc được mổ robot.

\section{BÀN LUẬN}

Từ những năm 1990 của thế kỷ trước, với sự phối hợp của NASA và Đại học Stanford, ý tưởng về dùng robot phẫu thuật trong vũ trụ được hình thành, mục đích có thể phẫu thuật điều khiển từ xa. Ý tưởng này sau đó được thương mại hoá và được FDA chấp thuận cho sử dụng dân sự. AESOP (Computer Motion, Inc., Goleta, CA, USA) là công ty đầu tiên đã dùng bàn đạp chân kết hợp bộ điều khiển từ xa tạo nên bộ điều khiển Zeus, ban đầu được thiết kế cho phẫu thuật tim, sau đó chứng tỏ khả năng có thể áp dụng cho các phẫu thuật khác. Cùng thời điểm, hệ thống phẫu thuật trực quan da Vinci (Intuitive Surgical, Sunnyvale, CA, USA) với những phát kiến tương tự cũng tham gia thị trường. Năm 2003 da Vinci hợp nhất chuyển động máy tính với phẫu thuật trực quan, trở thành nền tảng phẫu thuật robot duy nhất sử dụng trên thị trường hiện nay $(1,2)$. Trong vòng 15 năm sau đó, số lượng các ca mổ robot đãtăng lên không ngừng về cả số lượng lẫn vùng lãnh thổ sử dụng. Các phẫu thuật viên lồng ngực đã ứng dụng phẫu thuật robot vào lĩnh vực của mình rất thành công và an toàn. Phẫu thuật robot trở thành một lựa chọn cùng với phẫu thuật nội soi lồng ngực (VATS) thông thường làm tăng chất lượng cuộc mổ so với phẫu thuật mổ mở (3). Trong vòng 5 năm trở lại đây, với sự ra đời của những hệ thống robot mới như Xi vào năm 2014, hoạt động của hệ thống robot đã có những cải tiến vượt bậc. Stapler đã được gắn vào tay robot, camera có thể thay đổi ở các cổng trocar khác nhau như nội soi thông thường, phẫu thuật robot đã có những bước tiến ngoạn mục giúp xử lý những tình huống khó liên quan đến mạch máu, là yếu tố dễ gây nguy hiểm và chuyển sang mổ mở nhiều nhất trong phẫu thuật nội soi (4)

Theo khuyến cáo của hãng cũng như nhiều tác giả áp dụng, các lỗ vào (trocar) trong mổ robot thường là thẳng hàng trên một khoang liên sườn, trừ lỗ hỗ trợ ở cách 1 hoặc 2 khoang liên sườn phía dưới (5). Chúng tôi áp dụng đặt trocar hình tam giác như các mổ nội soi lồng ngực thông thường và thấy chúng hoạt động hiệu quả, giảm bớt được 1 lỗ vào (4 thay vì 5)

Việc đặt các trocar hình tam giác giúp các cánh tay robot hoạt động tốt hơn do đi trực tiếp tới vùng phẫu thuật hơn. Tuy nhiên do nguyên lý của các cánh tay robot, góc tạo bởi lỗ trocar cánh tay 1 , camera và cánh tay 2 phải lớn hơn hoặc bằng $90^{\circ}$, khoảng cách giữa các trocar cũng phải đủ lớn, ít nhất cũng bằng 4 khoát ngón tay $(\mathrm{H} .5)$ mới cho phép các cánh tay robot hoạt động dễ dàng và không cản trở tới hoạt động của người phụ phẫu thuật. Việc dùng nguyên lý tam giác trong phẫu thuật robot cũng giúp các phẫu thuật viên thấy việc giống nhau giữa phẫu thuật nội soi lồng ngực kinh điển (c- VATS) và phẫu thuật nội soi lồng ngực robot (r-VATS) về cả giải phẫu trường mổ lẫn các bước trong phẫu thuật đồng thời rất hữu ích cho việc dùng dao Harmonic cho cánh tay 1 (tay thuận của phẫu thuật viên) vì dao Harmonic không thể gập được như các dụng cụ robot khác. Việc giảm 1 cổng vào cũng giúp làm rộng các cổng khác thuận lợi cho phẫu thuật. Đặc biệt giúp phẫu thuật viên phụ mổ thoải mái trong việc hỗ trợ tại bàn mổ và dễ dàng dùng các dụng 
cụ hỗ trợ cũng như đưa các stapler vào thuận tiện, làm giảm đáng kể thời gian phẫu thuật.

Trước chúng tôi cũng có tác giả các đặt trocar hình tam giác nhưng chỉ bao gồm 5 ca cắt thuỳ phổi (6). Chúng tôi áp dụng cách đặt trocar hình tam giác cho tất cả những ca phẫu thuật robot của chúng tôi bao gồm cắt thuỳ phổi, cắt thực quản, cắt $\mathrm{u}$ cơ trơn thực quản, cắt $\mathrm{u}$ trung thất, cắt tuyến ức (có và không có $\mathrm{u}$ ), khẫu gấp nếp cơ hoành ...

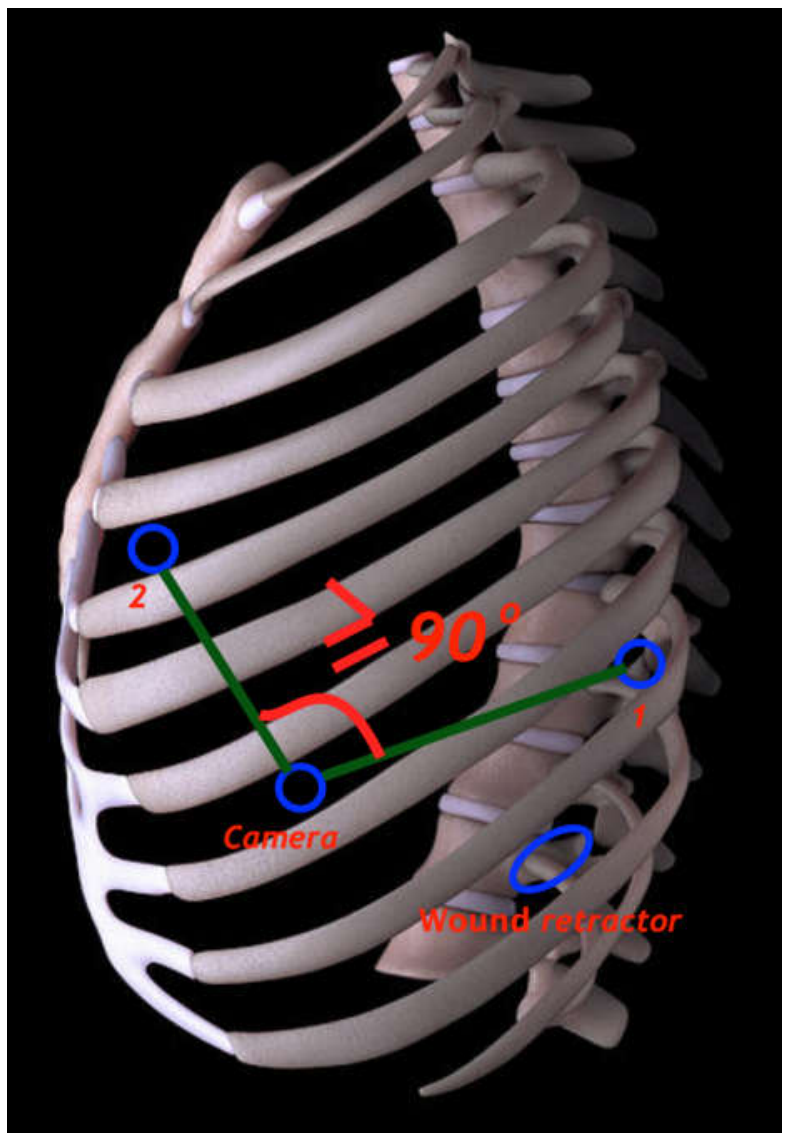

H. 5 Góc tạo bởi các lỗ trocar 1 và 2 và camera phải ít nhất là $90^{\circ}$. Khoảng cách giữa các trocar kể cả wound retractor phải ít bằng 4 khoát ngón tay

Chúng tôi không dùng bơm khí trong các phẫu thuật cắt thuỳ phổi mà chỉ dựa vào thông khí 1 phổi giống như phẫu thuật nội soi không dùng robot và thấy rất thuận tiện trong việc bóc tách cũng như cắt các mạch máu phổi hoặc phế quản. Đối với u trung thất hoặc thực quản thì có thể áp dụng bơm $\mathrm{CO} 2$ nhưng với việc xẹp phổi 1 bên tốt, chúng tôi thấy không cần bơm áp lực $\mathrm{CO} 2$ hỗ trợ. Đối với trung thất trước, trocar camera dưới mũi ức và bệnh nhân nằm ngửa, phẫu thuật cả 2 bên khoang ngực nên việc bơm khí áp lực làm rộng khoang sau xương ức trong lúc vẫn thông khí cả 2 phổi là cần thiết. Đường mổ này giúp phẫu thuật viên tư duy và thao tác tự tin giống như mổ mở với đường mổ chẻ xương ức. Những ca đầu tiên chúng tôi cũng vào 1 bên lồng ngực với thông khí 1 bên phổi nhưng sau đó chúng tôi thâý đường dưới mũi ức rất thuận lợi nên dùng chủ yếu đường này.

\section{KẾT LUẬN}

Phẫu thuật nội soi lồng ngực robot (rVATS) là an toàn, hiệu quả và có thể là một lựa 
chọn thay thế cho phẫu thuật nội soi lồng ngực thông thường (c- VATS). Việc áp dụng các vị trí đặt trocar hình tam giác như trong phẫu thuật nội soi thông thường có thể áp dụng tốt cho phẫu thuật nội soi lồng ngực robot. Đặt camera dưới mũi ức là thuận tiện cho phẫu thuật ở vùng trung thất trước như cắt tuyến ức, cắt $\mathrm{u}$ trung thất trước.

\section{TÀI LIỆU THAM KHẢO}

1. Lane T. A.Short history of robotic surgery. Ann R Coll SurgEngl 2018;100:5-7. 10.1308/rcsann.supp 1.5

2. Valero R, Ko YH, Chauhan S, et al. Robotic surgery: history and teaching impact. ActasUrolEsp 2011;35:540-5. 10.1016/j.acuro.2011.04.005

3. Kent, M., T. Wang, et al., Open, VideoAssisted Thoracic Surgery, and Robotic
Lobectomy: Review of a National Database. Ann ThoracSurg, 2014 Jan;97(1):236-42.

4. Carmelina C. Zirafa, Gaetano Romano, [...], and Franca Melfi. The evolution of robotic thoracic surgery. Ann Cardiothoracic Surg. 2019 Mar 8(2): 210 - 217

5. Robert J. Cerfolio, MD, Ayesha S. Bryant, MD, and Douglas J. Minnich, MD. Starting a Robotic Program in General Thoracic Surgery: Why, How, and Lessons Learned. Ann Thorac Surg 2011;91:1729-37

6. Bernard J. Park. A complete videoatlas of five robotic-assisted lobectomies. Masters of Cardiothoracic Surgery; Ann Cardiothorac Surg 2012;1(1):100-101. Scan to your mobile device or view video at: www.annalscts.com/article/view/484/580. 